\title{
Hand-Assisted Total Laparoscopic Hysterectomy of a 5200-Gram Uterus
}

\author{
Xiaoming Guan, MD, PhD, Anze Urh, MD, Teresa M. Walsh, MD, Vicki Ng, MD \\ Department of Obstetrics \& Gynecology, Baylor College of Medicine, Houston, TX, USA (Drs. Guan, Walsh). \\ Department of Obstetrics \& Gynecology, Brown University, Providence, RI, USA (Dr. Urh). \\ Department of Obstetrics \& Gynecology, St. Luke's Women's Center, San Francisco, CA, USA (Dr. Ng).
}

\begin{abstract}
Introduction: Hysterectomy is one of the most common gynecologic procedures performed. Minimally invasive laparoscopic techniques are preferred; however, laparotomy is still commonly performed for large uteri.
\end{abstract}

Case Description: We performed hand-assisted total laparoscopic hysterectomy of a 5200-g uterus.

Discussion: Hand-assisted laparoscopy is an alternative approach to laparotomy for large uteri and has similar benefits to traditional laparoscopic surgery. To our knowledge, the uterus in our patient is the largest uterus reported to have been removed laparoscopically.

Key Words: Large uterus, Fibroids, Hysterectomy, Laparoscopic hysterectomy, Hand assist.

Citation Guan X, Urh A, Walsh TM, Ng V. Hand-assisted total laparoscopic hysterectomy of a 5200-gram uterus. CRSLS e2014.00313. DOI: 10.4293/CRSLS.2014.00313.

Copyright (C) 2014 SLS This is an open-access article distributed under the terms of the Creative Commons Attribution-Noncommercial-ShareAlike 3.0 Unported license, which permits unrestricted noncommercial use, distribution, and reproduction in any medium, provided the original author and source are credited.

Address correspondence to: Xiaoming Guan, MD, PhD, Baylor College of Medicine, Houston, TX, 6651 Main Street, Suite F1050 Houston, Texas 77030, USA.

Telephone: (832) 826-7464, Fax: (832) 825-9349, E-mail: xiaoming@bcm.edu

\section{INTRODUCTION}

Hysterectomy is the most common major gynecologic operation performed in the world and one of the most common surgical procedures performed in the United States. ${ }^{1}$ The 2010 position statement of the American Association of Gynecologic Laparoscopists concluded that minimally invasive routes of hysterectomy should be the first choice for most patients with benign uteri. ${ }^{2}$ However, when a large uterus is encountered, the historical trend is to perform open laparotomy. Recent studies suggest that even a large uterus $(>500 \mathrm{~g})$ can be removed by a minimally invasive approach with similar outcomes to those procedures with a smaller uterine weight. ${ }^{3,4}$ This case reports the removal of a 5200-g uterus by a hand-assisted laparoscopic hysterectomy.

\section{CASE REPORT}

A 41-year-old woman presented for the definitive management of uterine fibroids and abnormal vaginal bleeding. She had a medical history of hypertension and obesity (body mass index, $43 \mathrm{~kg} / \mathrm{m}^{2}$ ). Her surgical history was significant for a previous cesarean delivery with a bilateral tubal ligation. The patient reported an increase in vaginal bleeding over a period of 1 year, as well as an increase in abdominal girth over the past few years, but denied any associated pelvic pain or pressure. Physical examination showed a 40 week-sized immobile uterus. Computed tomography imaging showed a $27 \times 25 \times 21-\mathrm{cm}$ uterus consistent with multiple leiomyoma; it occupied the entire abdomen and was within $4.4 \mathrm{~cm}$ of the xiphoid process (Figure 1) and within $2 \mathrm{~cm}$ of the liver's edge (Figure 2); No hydronephrosis was noted. The patient underwent a preoperative workup with no evidence of underlying malignancy. She was counseled about her possible options (including a laparotomy or a hand-assisted laparoscopic hysterectomy with possible conversion to an open procedure), and she opted to attempt to undergo a minimally invasive approach.

After induction of general anesthesia and placement of a nasogastric tube for suction, the left upper quadrant of the abdomen was entered with a 5-mm trocar under direct visualization with a laparoscope. The second trocar (10 $\mathrm{mm}$ ) was placed $2 \mathrm{~cm}$ below the xiphoid in the midline, 


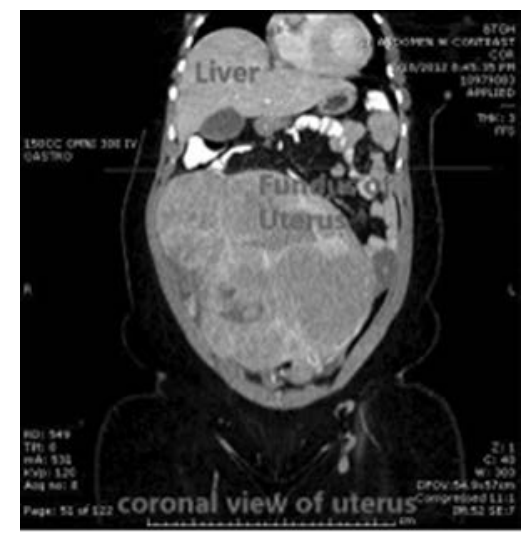

Figure 1. Coronal view. The uterine fundus extended to within $4.4 \mathrm{~cm}$ of the xiphoid process.

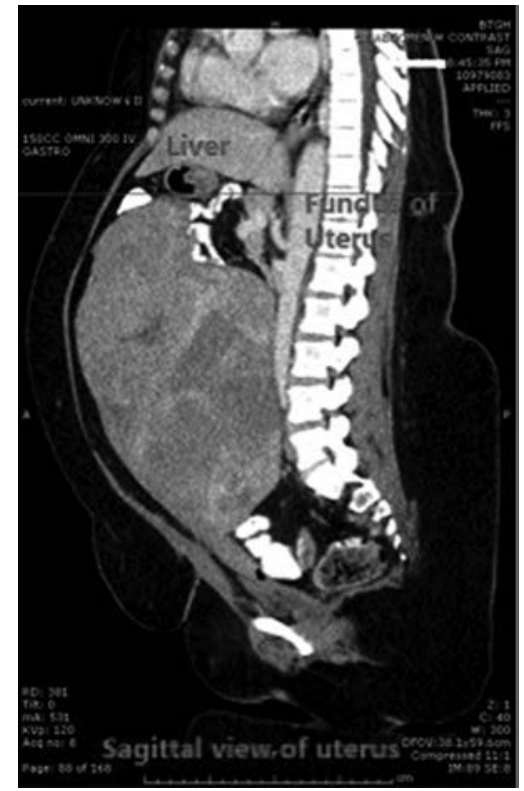

Figure 2. Sagittal view. The red line demarcates the upper extent of the uterine fundus, which came to within $2 \mathrm{~cm}$ of the liver's edge.

and the final 2 trocars (both $10 \mathrm{~mm}$ ) were placed laterally in the right and left upper quadrants. A $7-\mathrm{cm}$ vertical midline laparotomy was made $2 \mathrm{~cm}$ above the pubic symphysis (Figures 3 and 4). This laparotomy incision was then used to lyse adhesions from between the uterus and the anterior abdominal wall from the patient's prior cesarean section. A GelPort (Applied Medical, Rancho Santa Margarita, California) was then placed. This device is composed of 2 interlocking parts, an Alexis wound retractor (Applied Medical), which retracts and maximizes abdominal wall incisions to provide easy access to the

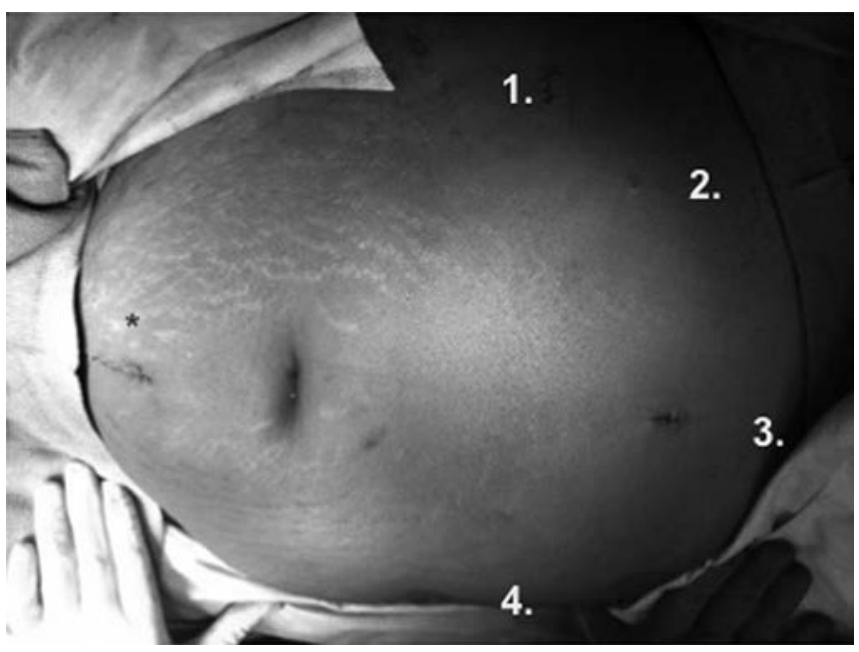

Figure 3. Postoperative view of trocar port incision sites after closure: right upper quadrant port (1), xiphoid camera port (2), entry and accessory port (ie, Palmer's point) (3), and left upper quadrant port (4). The asterisk indicates the hand-assisted GelPort.

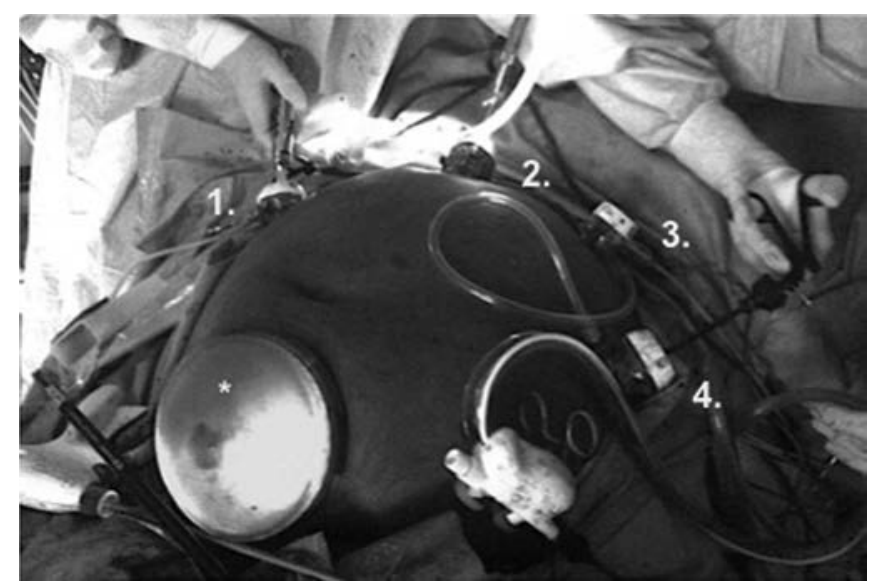

Figure 4. Intraoperative view of trocar port placement: right upper quadrant port, 10-mm trocar (1); xiphoid camera port, 10-mm trocar (2); entry and accessory port (ie, Palmer's point), 5-mm trocar (3); and left upper quadrant port, 10-mm trocar (4). The asterisk indicates the hand-assisted GelPort, with a $7-\mathrm{cm}$ incision.

surgical site, and a GelSeal cover (Applied Medical), which enables repetitive hand entry by an assistant without loss of the pneumoperitoneum. The uterus was poorly mobile because of its large size, but the use of a $45^{\circ}$ laparoscope and manipulation of the uterus with a gloved hand in the GelPort allowed for visualization of the surgical field. The uterus had significant vascular supply, and thorough coagulation of blood vessels with a bipolar de- 
vice was performed, before ligation with a $10-\mathrm{mm}$ LigaSure (Covidien, Mansfield, Massachusetts). The distorted anatomy prohibited proper placement of the manipulator preoperatively, and the uterus was initially amputated from the cervix at the level of the internal os. The GelPort cover was removed to allow access to the amputated uterus, and the specimen underwent manual morcellation with a scalpel (Figures 5 and 6). The GelPort cover was then replaced, and a laparoscopic trachelectomy was performed with the use of a sponge stick in the vagina. The vaginal cuff was closed with a No. 0 V-Loc running suture (Covidien), and a cystoscopy showed a normal bladder and bilateral ureteral function. The operation lasted 315 minutes, 80 minutes of which was used to perform morcellation of the large uterus. The estimated blood

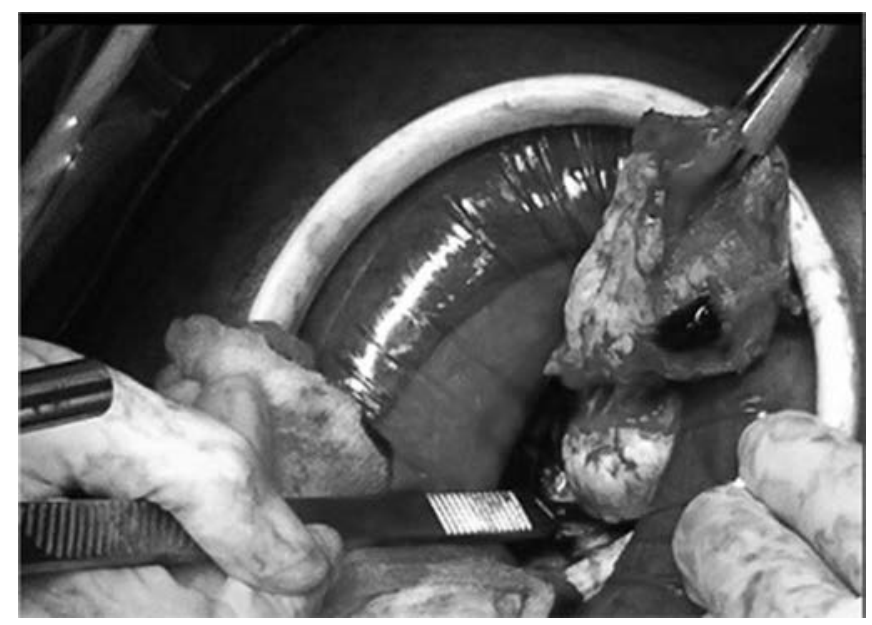

Figure 5. Intraoperative view of manual morcellation of uterus through GelPort (GelPort cover removed).

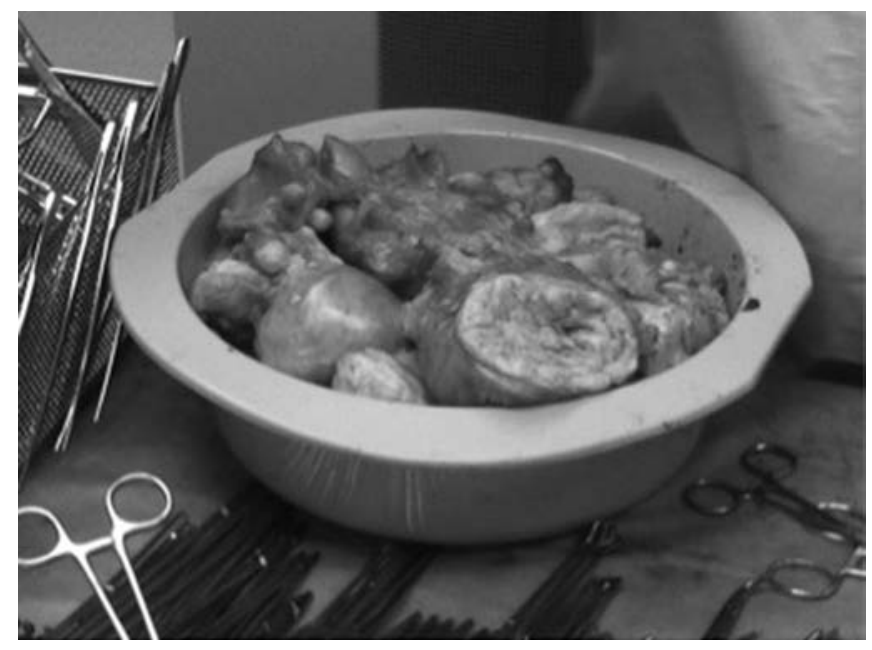

Figure 6. Uterus (final weight, $5200 \mathrm{~g}$ ) after morcellation. loss for the procedure was $120 \mathrm{~mL}$. The final weight of the surgical specimen was $5200 \mathrm{~g}$, and the findings of the pathologic examination were consistent with a benign fibroid uterus.

The patient did well the first day after surgery, but she was not discharged home until postoperative day 2 because of nausea and an episode of vomiting on postoperative day 1. Her postoperative course was unremarkable with a rapid return to her normal activities by the 2 -week follow-up visit.

\section{DISCUSSION}

To our knowledge, the uterus in our patient is the largest uterus to be removed by hand-assisted laparoscopy to date. The previously reported literature on laparoscopic hysterectomy with large uteri includes a case report by Demir and Marchand5 in 2010 with removal of a 3200-g uterus. The operation lasted 6 hours, and the patient was discharged home the second day after surgery with an unremarkable recovery. In 1999 Pelosi and Pelosi ${ }^{6}$ reported removal of a 3050-g uterus using the hand-assisted laparoscopic technique with a total operative time of 150 minutes. Uccella et $\mathrm{al}^{7}$ recently published a series of 71 cases of large uteri that underwent laparoscopic hysterectomy, and they found that laparoscopic hysterectomy had a high success rate and low complication rate in cases of uteri weighing $1000 \mathrm{~g}$.

The procedure in our patient took approximately 5 hours to complete, just over an hour of which was used to perform manual morcellation of the large uterus. Previous studies on laparoscopic uteri confirm that increased uterine size is associated with longer procedures. ${ }^{5-7}$

Techniques that we found helpful in completing the procedure through a minimally invasive approach were use of an angled laparoscope, changing of the trocar sites of the laparoscope throughout the procedure for better visualization, use of a hand through the GelPort to assist in retraction and manipulation, use of a reliable vessel sealing device, and sealing of all visualized vessels along the uterus before transection with a bipolar device.

Our case pushes the boundaries of laparoscopic surgery and challenges the limitation of laparoscopy with respect to uterine size. Some clinicians may argue that handassisted laparoscopy is not a traditional minimally invasive approach given the GelPort's incision size. We argue that a minimally invasive procedure must be defined in the context of the patient undergoing it. If our patient had 
undergone a traditional laparotomy to remove the large fibroid uterus, she would have required an incision well beyond the umbilicus and perhaps near the xiphoid. Instead, she had 5 small incisions with a significantly shorter postoperative recovery course. We support the notion that a minimally invasive approach should be considered for all benign hysterectomies regardless of size, and handassisted laparoscopy may be considered in all patients with extremely large uteri as an alternative to abdominal hysterectomy.

\section{References:}

1. DeFrances CJ, Lucas CA, Buie VC, Golosinskiy A. 2006 National Hospital Discharge Survey. Natl Health Stat Report. 2008;5:1-20.

2. AAGL Advancing Minimally Invasive Gynecology Worldwide. AAGL position statement. Route of hysterectomy to treat benign uterine disease. J Minim Invasive Gynecol. 2011;18: $1-3$.
3. Kondo W, Bourdel N, Marengo F, et al. Surgical outcomes of laparoscopic hysterectomy for enlarged uteri. J Minim Invasive Gynecol. 2011;18:310-313.

4. O'Hanlan KA, McCutcheon SP, McCutcheon JG. Laparoscopic hysterectomy: impact of uterine size. J Minim Invasive Gynecol. 2011;18:85-91.

5. Demir RH, Marchand GJ. Safe laparoscopic removal of a 3200 gram fibroid uterus. JSLS. 2010;14:600-602.

6. Pelosi MA, Pelosi MA III. Hand-assisted laparoscopy for complex hysterectomy. J Am Assoc Gynecol Laparosc. 1999;6(2): 183-188.

7. Uccella S, Cromi A, Serati M, Casarin J, Sturla D, Ghezzi F. Laparoscopic hysterectomy in case of uteri weighing $\geq 1$ kilogram: a series of 71 cases and review of the literature. J Minim Invasive Gynecol. 2013 Sep 4. pii: S1553-4650(13)01200. 